Proceedings

\title{
Depression, Anxiety, Stress and Physical Activity in Health-Re- lated University Students during COVID-19 †
}

\author{
Ivana Škrlec ${ }^{1, *}$, Jasminka Talapko ${ }^{1}$, Emina Pustijanac ${ }^{2}$ and Tomislav Meštrović ${ }^{3}$ \\ 1 Faculty of Dental Medicine and Health, Josip Juraj Strossmayer University of Osijek, HR-31000 Osijek, Croa- \\ tia; jtalapko@fdmz.hr \\ 2 Faculty of Natural Sciences, Juraj Dobrila University of Pula, HR-52100 Pula, Croatia emina.pustija- \\ nac@unipu.hr \\ 3 University Centre Varaždin, University North, HR-42000 Varaždin, Croatia; tmestrovic@unin.hr \\ * Correspondence: iskrlec@fdmz.hr
}

Publisher's Note: MDPI stays neutral with regard to jurisdictional claims in published maps and institutional affiliations.

\section{(c) (i)}

Copyright: $(\odot 2021$ by the authors. Submitted for possible open access publication under the terms and conditions of the Creative Commons Attribution (CC BY) license (http://creativecommons.org/licenses/by/4.0/).

\begin{abstract}
The coronavirus disease 2019 (COVID-19) pandemic led to the increased negative affective condition among university students. It is well-established that physical activity has positive effects on mental health and well-being, but due to gym closure as a restriction measure, levels of students' physical activity may decrease. This cross-sectional study aimed to define the levels of depressive, anxiety, and stress symptoms along with physical activity among health-related university students during the second partial COVID-19 lockdown. The survey included 212 students from the Faculty of Dental Medicine and Health of the University of Osijek in Croatia. To estimate the levels of depression, anxiety, and stress, the Depression Anxiety Stress Scale-21 (DASS-21) and the GodinShephard Leisure-Time Physical Activity Questionnaire (GSLTPAQ) questionnaires were used. The majority of students $(57.1 \%)$ reported increased stress levels during the second COVID-19 lockdown, and $58 \%$ reported decreased physical activity. A high prevalence of depressive $(52.8 \%)$, anxiety $(51.9 \%)$, and stress $(54.7 \%)$ symptoms were found among health-related university students, with $33 \%$ of students were insufficiently active. The results of this study suggested a high prevalence of negative affective conditions (depression, anxiety, and stress) and decreased physical activity among health-related university students during the second partial lockdown. The resulting symptoms were mostly of mild intensity; however, we consider this a significant mental health issue during the COVID-19 pandemic. It is crucial to monitor and promote students' mental health, especially in more affected females, to reduce the negative impact of this pandemic.
\end{abstract}

Keywords: anxiety; COVID-19; depression; physical activity; stress

\section{Introduction}

The coronavirus disease 2019 (COVID-19) pandemic, caused by the severe acute respiratory syndrome coronavirus 2 (SARS-CoV-2), is nowadays a major global health issue. Numerous introduced restriction measures have affected the mental and physical health of entire populations. Given the whole situation, it is essential to maintain a certain level of physical activity. This whole situation affected the stress level of the students. Stress is an etiological factor for many mental and physical illnesses, including anxiety and depressive disorders [1-3]. Psychological problems in students are a global problem and present a risk to their health, academic performance, and future careers [4]. University students are a population at risk for mental health, especially at the COVID-19 pandemic [4-6]. High levels of depression, anxiety, and stress are commonly reported among healthrelated university students [7]. Likewise, the current partial lockdown in Croatia could result in negative consequences on students' mental health. Previous studies have identified many stressors contributing to raised stress, anxiety, and depressive symptoms among students [8,9]. Nevertheless, the COVID-19 pandemic is associated with some new 
and previously rarely described risk factors. Restrictive measures may increase stress and psychological pressure on students because they are unable to fulfill their curriculum.

The period of lockdown and numerous restrictions will lead to social distress, followed by increased psychological tension and mental problems. Furthermore, the immediate health consequences, mental issues, and physical fitness influences might significantly impact public health $[10,11]$. The COVID-19 pandemic disrupts mental health services, and the most vulnerable youth population very rarely seeks help. During the initial phase of the COVID-19 pandemic, it was shown that the student population was at higher risk of anxiety, depression, and stress, in response to the outbreak of COVID-19 in comparison to older adults [3,6]. Also, physical activity can reduce harmful restriction measures and positively affect mental health [12]. Physical activity and exercise positively affect mental health, which is essential, especially in a pandemic $[6,10,13]$. If negative emotions (such as depression and anxiety) developed in the early stages of a pandemic remain without intervention, there is a possibility that it could lead to posttraumatic stress disorder.

The COVID-19 pandemic negatively affects students' mental health and physical activity. Therefore, this study aimed to specify the levels of anxiety, depression, and stress symptoms along with physical activity among health-related university students during the second partial COVID-19 lockdown in Croatia.

\section{Participants and Methods}

\subsection{Participants}

This cross-sectional study, conducted from $26^{\text {th }}$ November to $6^{\text {th }}$ December 2020, included 212 students (42 males and 170 females) from the Faculty of Dental Medicine and Health Osijek of the Josip Juraj Strossmayer University of Osijek. The Ethical Committee of the Faculty of Dental Medicine and Health Osijek approved the study, and all participants gave written informed consent. The study was conducted online according to the Declaration of Helsinki and its amendments.

\subsection{Questionaries}

Students were invited to complete a questionnaire containing three parts. In the first part, they were questioned about their socio-demographic, academic characteristics, and self-evaluation of mental stress and physical activity.

The second part consisted of the Depression Anxiety Stress Scale-21 (DASS-21). The DASS-21 questionnaire was used to assess the prevalence of stress, anxiety, and depression among students. Lovibond and Lovibond created the DASS-21 to measure negative affective conditions and discriminate between anxiety and depression [14]. We used a short, translated to Croatian, and validated version of DASS-21 [15,16]. DASS-21 consists of three subscales. The first is depression, which focuses on a bad mood, motivation, and self-esteem. The second is anxiety, based on psychological excitement, panic, and fear. The third subscale is stress, and it focuses on tension and irritability. DASS-21 scores were classified as normal, mild, moderate, severe, and extremely severe [14,17].

In the third part, students were asked about their physical activity using the GodinShephard Leisure-Time Physical Activity Questionnaire (GSLTPAQ). This questionnaire reports the self-assessment leisure-time physical activity [18]. Weekly frequencies of mild, moderate, and strenuous activities are multiplied by three, five, and nine. For health benefit, we took only the reported frequency of moderate and strenuous activities into the calculation. Obtained categories correspond to active - more than 24 units, moderately active between 14 and 23 units, and insufficiently active less than 14 units [19].

\subsection{Statistical analyses}

A Kolmogorov-Smirnov test was used to evaluate the normality of the data distribution. All numerical variables deviated from a normal distribution. The categorical data were presented with absolute and relative frequencies, while numerical data were described with medians and interquartile ranges (IQR). Mann-Whitney and chi-square tests 
were used to compare the numerical and categorical data between two groups. The pvalue of $<0.05$ was considered statistically significant. The analyses were completed using SPSS software (ver. 22.0, SPSS Inc., Chicago, IL, USA).

\section{Results and Discussion}

We questioned a total of 212 students with a median age of 25 (21-38). Socio-demographic data and self-elevated mental stress and physical activity are presented in Table 1. In the study participated more female and undergraduate students because of student body consisting dominantly of the female. During the second partial lockdown, female students reported increased mental stress and decreased physical activity compared to their male counterparts.

Table 1. Socio-demographic data and self-assessment of mental stress and physical activity.

\begin{tabular}{|c|c|c|c|c|}
\hline Variable & $\begin{array}{c}\text { Male } \\
42(19.8 \%)\end{array}$ & $\begin{array}{c}\text { Female } \\
170(82.2 \%)\end{array}$ & $\begin{array}{c}\text { All students } \\
212(100 \%)\end{array}$ & p-value \\
\hline Age, years & $25(21-38)$ & $25(21-38)$ & $25(21-38)$ & $0.886^{*}$ \\
\hline \multicolumn{5}{|c|}{ Study } \\
\hline Nursing & $23(54.8 \%)$ & $148(87.1 \%)$ & $171(80.7 \%)$ & \multirow{3}{*}{$<0.001 \dagger$} \\
\hline Dental medicine & $16(38.1 \%)$ & $14(8.2 \%)$ & $30(14.2 \%)$ & \\
\hline Physical Therapy & $3(7.1 \%)$ & $8(4.7 \%)$ & $4(5.2 \%)$ & \\
\hline \multicolumn{5}{|l|}{ Study program } \\
\hline Undergraduate & $28(66.7)$ & $103(60.6)$ & $131(61.8)$ & \multirow{2}{*}{$0.46+$} \\
\hline Graduate & $14(33.3)$ & $67(39.4)$ & $80(37.7)$ & \\
\hline GPA & $4(3.7-4.1)$ & $4(3.7-4.13)$ & $4(3.7-4.1)$ & $0.94^{*}$ \\
\hline BMI & $26.58(24.71-29.14)$ & $23.04(20.57-23.04)$ & $23.64(21-26.88)$ & $<0.001^{*}$ \\
\hline \multicolumn{5}{|c|}{ Mental stress } \\
\hline Reduced & $3(7.1 \%)$ & $4(2.4 \%)$ & $7(3.3 \%)$ & \multirow{3}{*}{$0.029 t$} \\
\hline Constant & $22(52.4 \%)$ & $62(36.5)$ & $84(39.6 \%)$ & \\
\hline Increased & $17(40.5 \%)$ & $104(61.2)$ & $121(57.1 \%)$ & \\
\hline \multicolumn{5}{|c|}{ Physical activity } \\
\hline Reduced & $24(57.1 \%)$ & $99(58.2 \%)$ & $123(58 \%)$ & \multirow{3}{*}{$0.50+$} \\
\hline Constant & $14(33.3 \%)$ & $45(26.5 \%)$ & $59(27.8 \%)$ & \\
\hline Increased & $4(9.5 \%)$ & $26(15.3 \%)$ & $30(14.2 \%)$ & \\
\hline
\end{tabular}

* Mann-Whitney test; +Chi-square test.

Correlations between the numeric variables are presented in Table 2. Depression was strongly positively correlated with anxiety and stress; moreover, anxiety was also positively correlated with stress. However, no correlation was observed between negative affective conditions and physical activity. In contrast, other research found that physical activity is positively correlated with mental health [13].

Table 2. Correlations of age, GPA, BMI, scores of the Depression Anxiety Stress Scale-21 (DASS-21), and Physical Activity (GSLTPAQ) scales (n=212).

\begin{tabular}{ccccccc}
\hline & GPA & BMI & Depression & Anxiety & Stress & Physical Activity \\
\hline Age & -0.001 & $0.182^{* *}$ & -0.093 & -0.068 & -0.022 & $-0.146^{*}$ \\
\hline GPA & & 0.150 & -0.013 & -0.010 & -0.032 & -0.028 \\
\hline BMI & & -0.016 & -0.020 & -0.300 & -0.038 \\
\hline Depression & & & $0.794^{* *}$ & $0.841^{* *}$ & 0.052 \\
\hline Anxiety & & & & $0.860^{* *}$ & -0.087 \\
\hline Stress & & & & & -0.036 \\
\hline
\end{tabular}


Gender-related differences of the DASS-21 and the Godin-Shephard Leisure-Time Physical Activity Questionnaire are shown in Figure 1. It is observed that female students had significantly higher levels of negative affective conditions than male students. The results show that female students probably have more significant mental health problems. Previous studies have also shown that female students are more likely to develop depression and anxiety $[6,7,10]$.

Female students scored lower on physical activity than their male counterparts. Physical activity in leisure time has a positive effect on mental health and well-being. Reduced physical activity is a risk factor for elevated mental stress $[10,13]$. That is especially evident during COVID-19 lockdown, as leisure time increases while exercise and sports are limited.

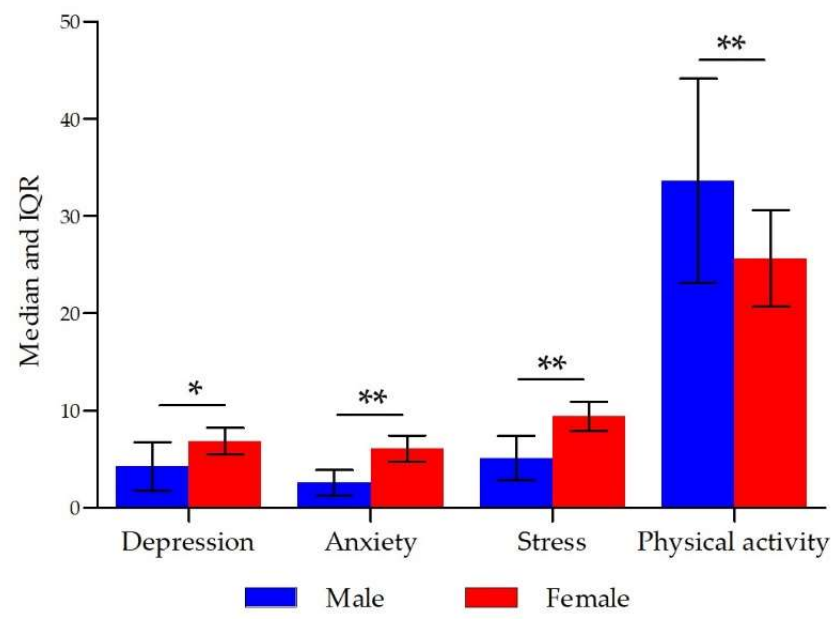

Figure 1. Gender-related differences of students' scores on the Depression Anxiety Stress Scale-21 (DASS-21) and the Godin-Shephard Leisure-Time Physical Activity Questionnaire ( $\mathrm{n}=212)$. ${ }^{*}$ Mann-Whitney U test $\mathrm{p}<0.05,{ }^{* *}$ Mann-Whitney $\mathrm{U}$ test $\mathrm{p}<0.001$. IQR - interquartile range.

The prevalence of the DASS-21 and Godin-Shephard Leisure-Time Physical Activity Questionnaire, divided by categories based on pre-defined cut points, are shown in Table 3. The majority of the male students were scored within the normal range for symptoms of depression, anxiety, and stress. Two-thirds of female students showed significant anxiety and stress symptoms, while slightly more than half of the female students were depressed. The differences between the two groups are statistically significant. At the same time, more than a third of female students are insufficiently physically active. Based on the results obtained, we can say that higher physical activity is related to lower levels of anxiety, stress, and depression. Gender has a significant impact on the severity of anxiety, stress, and depression symptoms, as seen in other studies [3,4].

Table 3. The prevalence of the categories of depressive, anxiety, and stress symptoms according to the Depression Anxiety Stress Scale-21 (DASS-21) and Godin-Shephard Leisure-Time Physical Activity Questionnaire (GSLTPAQ). Groups are divided by gender $(n=212)$.

\begin{tabular}{|c|c|c|c|c|c|}
\hline & DASS-21 & Males, n (\%) & Females, n (\%) & All students, $\mathbf{n}(\%)$ & p-value \\
\hline \multirow{5}{*}{ 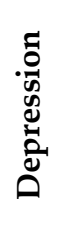 } & Normal & $25(59.5)$ & $75(44.1)$ & $100(47.2)$ & \multirow{5}{*}{0.003} \\
\hline & Mild & $4(9.5)$ & $18(10.6)$ & $22(10.4)$ & \\
\hline & Moderate & $8(19)$ & $29(17.1)$ & 37 (17.5) & \\
\hline & Severe & $4(9.5)$ & $25(14.7)$ & $29(13.7)$ & \\
\hline & Extremely severe & $1(2.4)$ & $23(13.5)$ & $24(11.3)$ & \\
\hline \multirow{3}{*}{ 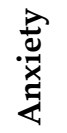 } & Normal & $31(73.8)$ & $71(41.8)$ & $102(48.1)$ & \multirow{3}{*}{$<0.001$} \\
\hline & Mild & $5(11.9)$ & $28(16.5)$ & 33 (15.6) & \\
\hline & Moderate & 0 & $9(5.3)$ & $9(4.2)$ & \\
\hline
\end{tabular}




\begin{tabular}{|c|c|c|c|c|c|}
\hline & Severe & $3(7.1)$ & $14(8.2)$ & $17(8)$ & \\
\hline & Extremely severe & $3(7.1)$ & $48(28.2)$ & $51(24.1)$ & \\
\hline \multirow{5}{*}{ के } & Normal & $29(69)$ & $67(39.4)$ & $96(45.3)$ & \multirow{5}{*}{$<0.001$} \\
\hline & Mild & $4(9.5)$ & $27(15.9)$ & $31(14.6)$ & \\
\hline & Moderate & $2(4.8)$ & $20(11.8)$ & $22(10.4)$ & \\
\hline & Severe & $7(16.7)$ & $28(16.5)$ & $35(16.5)$ & \\
\hline & Extremely severe & 0 & $28(16.5)$ & $28(13.2)$ & \\
\hline \multirow{3}{*}{ 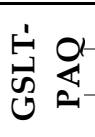 } & Active & $26(61.9)$ & $71(41.8)$ & $97(45.8)$ & \multirow{3}{*}{0.008} \\
\hline & Moderately active & $9(21.4)$ & $36(21.2)$ & $45(21.2)$ & \\
\hline & Insufficiently active & $7(16.7)$ & $63(37.1)$ & $70(33)$ & \\
\hline
\end{tabular}

\section{Conclusions}

This study highlights that students are at the highest risk for psychological distress during the COVID-19 pandemic. During the COVID-19 pandemic, efforts are required to improve positive mental health and well-being. This research indicates that physical activity is good for promoting health and well-being during times of uncertainty. Universities should offer early detection and prevention programs. Interventions for depression and anxiety among students should be conducted before graduation since it may have long-term effects on their future careers as healthcare professionals. Finally, it is essential to monitor and promote students' mental health, particularly in more affected women, to reduce the pandemic's adverse effects.

Author Contributions: Conceptualization, I.Š. and J.T.; methodology, E.P.; formal analysis, I.Š. and T.M.; data curation, I.Š. and J.T.; writing-original draft preparation, I.Š.; writing-review and editing, J.T., E.P., and T.M.; visualization, I.Š.; supervision, T.M. All authors have read and agreed to the published version of the manuscript.

Funding: This research received no external funding.

Conflicts of Interest: The authors declare no conflict of interest. The funders had no role in the design of the study; in the collection, analyses, or interpretation of data; in the writing of the manuscript, or in the decision to publish the results.

\section{References}

1. Henry, J. D.; Crawford, J. R. The short-form version of the Depression anxiety stress scales (DASS-21): Construct validity and normative data in a large non-clinical sample. Br. J. Clin. Psychol. 2005, 44, 227-239, doi:10.1348/014466505X29657.

2. Szabó, M. The short version of the Depression Anxiety Stress Scales (DASS-21): Factor structure in a young adolescent sample. J. Adolesc. 2010, 33, 1-8, doi:10.1016/j.adolescence.2009.05.014.

3. Wang, X.; Hegde, S.; Son, C.; Keller, B.; Smith, A.; Sasangohar, F. Investigating mental health of US college students during the COVID-19 pandemic: Cross-sectional survey study. J. Med. Internet Res. 2020, 22, e22817, doi:10.2196/22817.

4. Atkinson, S. R. Elevated psychological distress in undergraduate and graduate entry students entering first year medical school. PLoS One 2020, 15, doi:10.1371/journal.pone.0237008.

5. Stormon, N.; Ford, P. J.; Kisely, S.; Bartle, E.; Eley, D. S. Depression, anxiety and stress in a cohort of Australian dentistry students. Eur. J. Dent. Educ. 2019, 23, 507-514, doi:10.1111/eje.12459.

6. Wathelet, M.; Duhem, S.; Vaiva, G.; Baubet, T.; Habran, E.; Veerapa, E.; Debien, C.; Molenda, S.; Horn, M.; Grandgenèvre, P.; Notredame, C.-E.; D'Hondt, F. Factors Associated With Mental Health Disorders Among University Students in France Confined During the COVID-19 Pandemic. JAMA Netw. Open 2020, 3, e2025591, doi:10.1001/jamanetworkopen.2020.25591.

7. Milić, J.; Škrlec, I.; Milić Vranješ, I.; Podgornjak, M.; Heffer, M. High levels of depression and anxiety among Croatian medical and nursing students and the correlation between subjective happiness and personality traits. Int. Rev. Psychiatry 2019, 31, 1-8, doi:10.1080/09540261.2019.1594647.

8. Knipe, D.; Maughan, C.; Gilbert, J.; Dymock, D.; Moran, P.; Gunnell, D. Mental health in medical, dentistry and veterinary students: cross-sectional online survey. BJPsych Open 2018, 4, 441-446, doi:10.1192/bjo.2018.61.

9. Donker, T.; van Straten, A.; Marks, I.; Cuijpers, P. Quick and easy self-rating of Generalized Anxiety Disorder: Validity of the Dutch web-based GAD-7, GAD-2 and GAD-SI. Psychiatry Res. 2011, 188, 58-64, doi:10.1016/j.psychres.2011.01.016.

10. Schlichtiger, J.; Brunner, S.; Steffen, J.; Huber, B. C. Mental health impairment triggered by the COVID-19 pandemic in a sample population of German students. J. Investig. Med. 2020, jim-2020-001553, doi:10.1136/jim-2020-001553. 
11. Saladino, V.; Algeri, D.; Auriemma, V. The Psychological and Social Impact of Covid-19: New Perspectives of Well-Being. Front. Psychol. 2020, 11, doi:10.3389/fpsyg.2020.577684.

12. Luciano, F.; Cenacchi, V.; Vegro, V.; Pavei, G. COVID-19 lockdown: physical activity, sedentary behaviour and sleep in Italian medicine students. Eur. J. Sport Sci. 2020, 1-22, doi:10.1080/17461391.2020.1842910.

13. Maher, J. P.; Hevel, D. J.; Reifsteck, E. J.; Drollette, E. S. Physical activity is positively associated with college students' positive affect regardless of stressful life events during the COVID-19 pandemic. Psychol. Sport Exerc. 2020, 52, 101826, doi:10.1016/j.psychsport.2020.101826.

14. Lovibond, P. F.; Lovibond, S. H. The structure of negative emotional states: Comparison of the Depression Anxiety Stress Scales (DASS) with the Beck Depression and Anxiety Inventories. Behav. Res. Ther. 1995, 33, 335-343, doi:10.1016/0005-7967(94)00075U.

15. Ivaković, F. Skale depresije, anksioznosti i stresa DASS-S i DASS-O Priručnik; Zagreb, 2019;

16. Ivezić, E.; Jakšić, N.; Jokic-Begic, N.; Suranyi, Z. Validation of the Croatian adaptation of the Depression, Anxiety, Stress Scales - 21 (DASS-21) in a clinical sample. In 18th Psychology Days; Zadar, 2012; p. 1.

17. Parkitny, L.; McAuley, J. The depression anxiety stress scale (DASS). J. Physiother. 2010, 56, 204, doi:10.1016/s1836-9553(10)700308.

18. Godin, G.; Shephard, R. J. A simple method to assess exercise behavior in the community. Can. J. Appl. Sport Sci. 1985, 10, 141146.

19. Godin, G. The Godin-Shephard Leisure-Time Physical Activity Questionnaire. Heal. Fit. J. Canada 2011, 4, 18-22, doi:https://doi.org/10.14288/hfjc.v4i1.82. 